in vivo $35: 721-729(2021)$

doi:10.21873/invivo.12313

\title{
Effect of Kinase Inhibitors on the Technetium-99m Uptake into Thyroid Carcinoma Cells In Vitro
}

\author{
ANNA ANSCHLAG ${ }^{1}$, BRANDON H. GREENE ${ }^{2}$, LORIANNA KÖNNEKER $^{3}$, MARKUS LUSTER $^{4}$, \\ JAMES NAGARAJAH ${ }^{5}$, SABINE WÄCHTER ${ }^{6}$, ANNETTE WUNDERLICH $^{6}$ and ANDREAS PFESTROFF \\ ${ }^{1}$ Department of Child and Adolescent Psychiatry, University Hospital of Marburg, Marburg, Germany; \\ ${ }^{2}$ Bio 21 Institute, CSL Limited Melbourne, Parkville, VIC, Australia; \\ ${ }^{3}$ Department of Virology, Hospital Nordwest Frankfurt, Frankfurt, Germany; \\ ${ }^{4}$ Department of Nuclear Medicine, University Hospital of Marburg, Marburg, Germany; \\ ${ }^{5}$ Department of Nuclear Medicine, Klinikum Rechts der Isar, Technical University of Munich, Munich, Germany; \\ ${ }^{6}$ Department of Visceral, Thoracic and Vascular Surgery, University Hospital of Marburg, Marburg, Germany
}

\begin{abstract}
Background/Aim: We evaluated the potential of the kinase inhibitors sorafenib, lenvatinib and selumetinib on increasing the uptake of technetium-99m into thyroid cancer cells. Materials and Methods: Four established cell lines and three patient's cell cultures were treated with 0.1, 1 and $5 \mu M$ of sorafenib, lenvatinib and selumetinib for 72 hours. After incubation with $1 \mathrm{MBq}$ of technetium-99m, the radioactivity uptake was measured. Results: The experiments showed heterogeneous results. Maximum technetium-99m uptake increases of $312 \%$ (sorafenib), $326 \%$ (lenvatinib) and $759 \%$ (selumetinib) were obtained using the highest applied concentrations. In some tests, an uptake reduction or no effect was observed. Conclusion: Kinase inhibitors have a positive effect on technetium-99m uptake. Due to study limitations, a redifferentiating effect of the drugs could not be definitely proven. Unspecific cytotoxicity might have a confounding effect.
\end{abstract}

Thyroid carcinoma is the most common endocrine tumor with a ten-year-prevalence of nearly 60,000 cases and an incidence of over 7,000 new diagnoses per year in Germany, women being affected twice as often as men. Cancer of the thyroid gland accounted for almost 700 deaths in that same year in this country (1). Worldwide, the incidence for all ages reached approximately 230,000 cases in 2019, with a similar

This article is freely accessible online.

Correspondence to: Anschlag Anna, Department of Child and Adolescent Psychiatry, University Hospital of Marburg, Baldingerstr. 1, D-35043 Marburg, Germany. Tel: +49 64215864144, Fax: +49 64215864142,e-mail: anschlaa@staff.uni-marburg.de

Key Words: Thyroid carcinoma, radioiodine-refractory thyroid cancer, multikinase inhibitor, redifferentiation. distribution between the genders, and above 45,000 deaths were recorded globally due to malignant thyroid disease (2). Its manifestations can be subdivided into different categories. Differentiated thyroid carcinomas (DTC), accounting for about $85 \%$ of all thyroid cancers, derive from the follicular epithelium and include papillary (PTC) as well as follicular thyroid carcinoma (FTC), and a couple of rare subtypes. Medullary thyroid cancers (MTC) are developed from calcitonin producing C-cells, whereas the highly aggressive anaplastic thyroid carcinomas (ATC) are composed of dedifferentiated tissue. Poorly differentiated thyroid carcinomas (PDTC) represent a separate entity in-between DTC and ATC and - among other markers of dedifferentiation including signs of malignancy such as invasion or metastasis, aberrant nuclear formations and necrosis - show a reduced radio-iodine avidity $(3,4)$. The standardized treatment for DTC, consisting of thyroidectomy and adjuvant iodine-131radioiodine (I-131) therapy, provides a 10-year survival rate up to $98 \%$ for local tumors, which is nearly equal to the healthy population (5-7). About $10 \%$ of all DTC develop metastatic progressive diseases, some of them presenting with mutations alongside intracellular signaling cascades impairing natural feedback mechanisms. The result is often a decrease or loss of the ability to metabolize iodine, which consequentially causes a low response to treatment with radioactive iodine and a drop in 10-year survival rates to roughly $10 \%(8-10)$. While there is still no consistent definition of radioiodine-refractory thyroid disease, characteristics such as the presence of lesions irresponsive to I-131 therapy, progression of lesions within 6 to 12 months after radioiodine treatment as well as high fluorodeoxyglucose (F-18-FDG)-avidity are associated with this clinical situation (9). Experimental treatments with systemic doxorubicin-based therapy, external radiation or local ablative measures remained poorly effective (11). Lately, kinase inhibitors (KIs) have 
Table I. Characteristics of used cells in culture. The table gives an overview of the carcinoma types and the known mutations of the reference cell lines as well as the extracted primary cell cultures that were used in the experiments of this study.

\begin{tabular}{|c|c|c|c|c|c|c|c|}
\hline \multirow{6}{*}{$\begin{array}{l}\text { Cell line } \\
\text { Type } \\
\text { Mutation }\end{array}$} & \multicolumn{7}{|c|}{ Characteristics of cells } \\
\hline & \multicolumn{4}{|c|}{ Reference cell lines } & \multicolumn{3}{|c|}{ Primary cell cultures } \\
\hline & TPC1 & C-643 & $8505 \mathrm{C}$ & BCPAP & PC-01 & PC-02 & PC- 03 \\
\hline & PTC & ATC & ATC & PDTC & PDTC & ATC & ATC \\
\hline & RET/PTC & TP53 & TP53 & TP53 & TP53 & & V600E-BRAF \\
\hline & HRAS & HRAS & $\begin{array}{c}\text { V600E-BRAF } \\
\text { HRAS }\end{array}$ & V600E-BRAF & & & \\
\hline
\end{tabular}

emerged as a promising new therapeutic approach in radioiodine refractory thyroid cancer. The multikinase inhibitors sorafenib and lenvatinib were officially approved by the U.S. Food and Drug Administration (FDA) for this indication and are recommended as an additional treatment option in cases of radioidine-refractory progressive thyroid cancer with high tumor burden or rapid progression by the 2019 European Thyroid Association (ETA) Guidelines in the doses of $400 \mathrm{mg}$ twice and $24 \mathrm{mg}$ once daily, respectively, under careful follow-up in regular intervals for at least 6 months (3). In addition, the specific mitogen-activated protein kinase kinase (MEK) inhibitor selumetinib was able to restore a partial redifferentiation and consecutive radioiodine uptake in a subset of 12 out of 20 patients in a pilot study (10), while a phase III clinical trial could not prove a significant effect of selumetinib treatment on the complete remission rates when compared to placebo. Another phase II study aimed at assessing the redifferentiation potential of selumetinib is currently in recruiting stage (12). Despite the potential benefits of the application of KIs in advanced and otherwise hardly manageable stages of thyroid cancer, their use is discussed controversially due to low remission rates, long-term loss of action and high toxicity with severe adverse effects, including hand-foot-syndrome, hypertension, diarrhea, weight loss and fatigue, and therefore often requiring pausing, dose reduction or even termination of treatment (9).

The aim of this study was to evaluate the effect of sorafenib, lenvatinib and selumetinib on increasing the uptake of technetium-99m, as a surrogate for radioiodine uptake, into a selection of different human thyroid carcinoma cells in vitro.

\section{Materials and Methods}

The tests were conducted in seven different cell lines. Four of them were established human thyroid carcinoma cell lines: the well differentiated culture TPC1, the poorly differentiated thyroid cancer cell line BCPAP, as well as the cell lines C-643 and 8505C, both ATC. TPC1 and C-643 cells were provided by Prof. A. Zielke (Diakonie-Klinikum Stuttgart, Stuttgart, Germany). BCPAP and
8505C cell lines were purchased from DSMZ (Leibnitz Institute DSMZ-German Collection of Microorganisms and cell Cultures, Braunschweig, Germany). Furthermore, we used surgically extracted and cultivated primary tumor cells from three patients that will furtherly be referred to as PC-01, PC-02 and PC- 03 . The first primary culture was taken from a lymph node metastasis of a PDTC in 2014, while the other two were extracted from primary thyroid tumors classified as ATC in 2014 (PC-02) and 2015 (PC-03). They were all acquired in the Department of Visceral, Thoracic and Vascular Surgery of the University Hospital of Marburg and have not been authenticated. Sorafenib, lenvatinib and selumetinib were provided by Selleck Chemicals (Houston, TX, USA) and dissolved in Dimethyl sulfoxide (DMSO). Stock solutions of sorafenib and lenvatinib $(10 \mathrm{mM})$ were stored at $-20^{\circ} \mathrm{C}$; stock solution of selumetinib $(20 \mu \mathrm{M})$ was stored at $-80^{\circ} \mathrm{C}$. Table I summarizes the carcinoma types and the mutational status of all processed cell lines.

This research study was conducted retrospectively from material obtained for clinical purposes. Ethical approval for the acquisition and processing of the cells from our patients was granted from the Institutional Review Board of the University Hospital of Marburg in the context of earlier clinical studies (AZ 166/09, AZ 92/15). Informed consent was obtained from all individual participants included in the study.

Each test run required seven 6-well-plates that were labelled and processed as shown in Figure 1.

Each experiment began with the placement of $1 \times 10^{5}$ cells of the selected culture into each well except for the blank value plates, followed by a 24-h period of adhesion in an incubator. The following day, the cells were treated with either sorafenib, lenvatinib or selumetinib in the three different concentrations of 0.1 , 1 and $5 \mu \mathrm{M}$ and left to incubate for $72 \mathrm{~h}$. We chose equally low KI dosages in this range - based on the cytoviability observations in a previous in vitro study performed on a primary cell culture at our hospital with sorafenib (13) - in order to reduce cell death caused by unspecific toxicity, especially in the unstable primary cell cultures, as well as to ameliorate comparability. For the final measurements, excess fluid from the blank value plates was removed and replaced with $1 \mathrm{ml}$ of 3-(4,5-dimethylthiazol-2-yl)-2,5diphenyltetrazolium bromide (MTT) and the plates were stored in the incubator for $3 \mathrm{~h}$. After that, the liquid was drained and an equivalent amount of stopping solution - composed of $17 \mathrm{ml}$ isopropanol, $3 \mathrm{ml}$ sodium dodecyl sulfate (SDS) $20 \%$ and $0.8 \mathrm{ml}$ 10-molar hydrochloric acid - was applied to each well for $30 \mathrm{~min}$. The detergent solution caused an arrest in the cellular metabolism and allowed the differentiation of vital cells through their 
Blank value plate

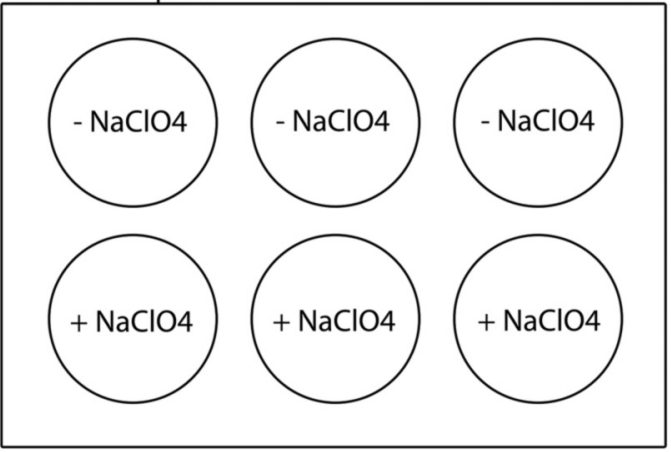

Referencing plate $0.1 \mu \mathrm{M}$
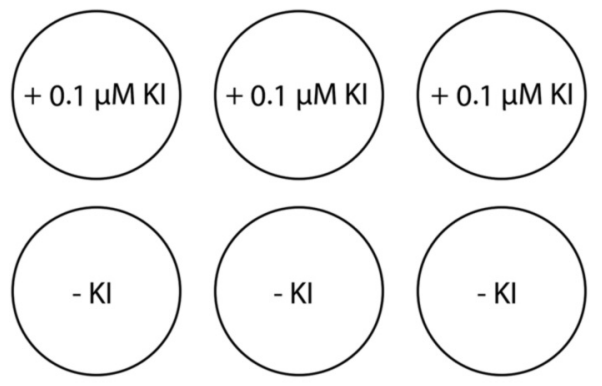

Measuring plate $0.1 \mu \mathrm{M}$ without blockade

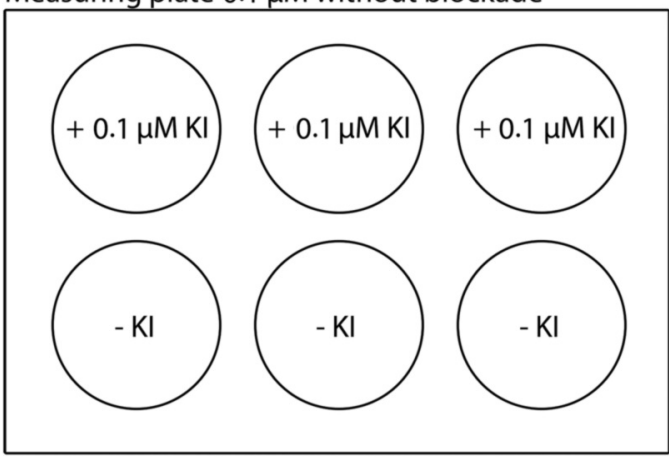

Measuring plate $1 \mu \mathrm{M}$

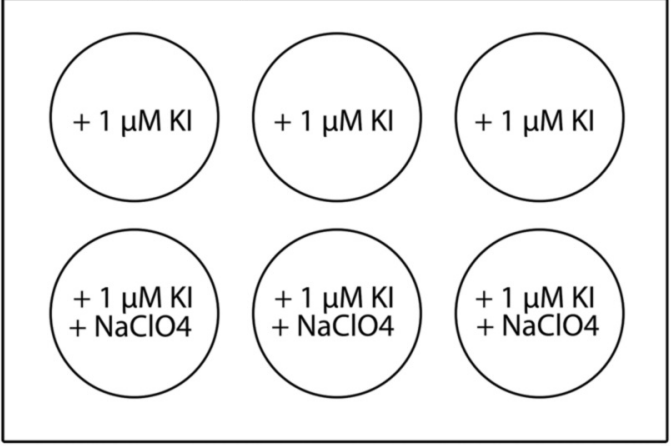

Referencing plate $1 \mu \mathrm{M} \& 5 \mu \mathrm{M}$

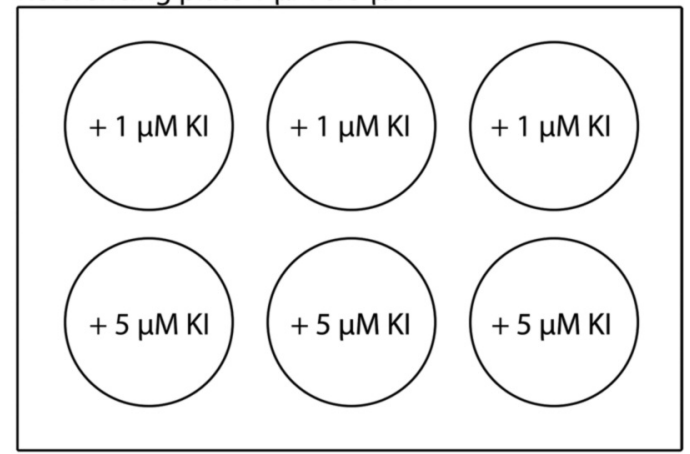

Measuring plate $0.1 \mu \mathrm{M}$ with blockade

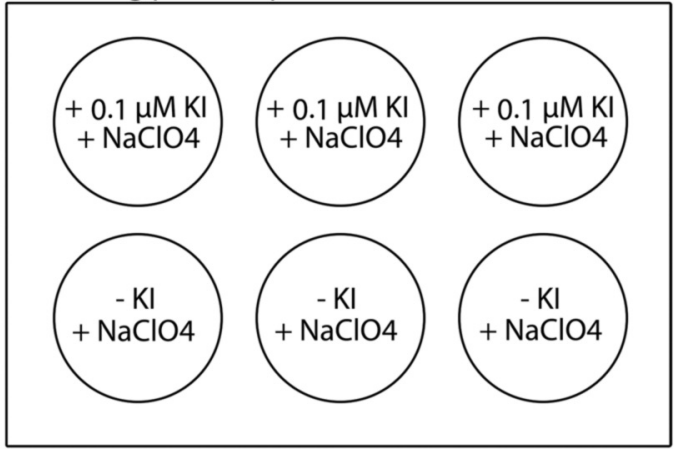

Measuring plate $5 \mu \mathrm{M}$

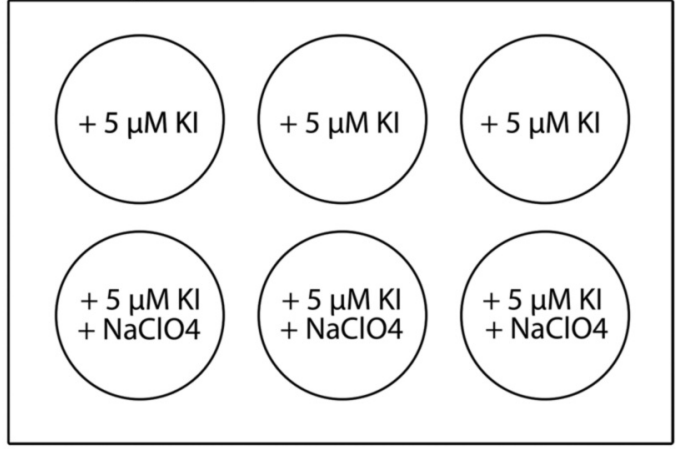

Figure 1. Preparation of the six-well plates for the experiments. The blank value plate contained no cells and was partially incubated with sodium perchlorate monohydrate ( $\mathrm{NaClO4}$, furtherly referred to as perchlorate) blockade solution. The two referencing plates were used for the assessment of cytoviability. For each treatment concentration, a series of six wells were incubated with a fixed number of cells as well as the respective kinase inhibitor (KI). Of those, three wells remained without further manipulation, while the other three received a perchlorate blockade to serve as a negative control for the later technetium-99m uptake assessment. The baseline values for comparison of uptake measurements under KI treatment received no KI treatment, but were also defined separately with and without blockade solution. 

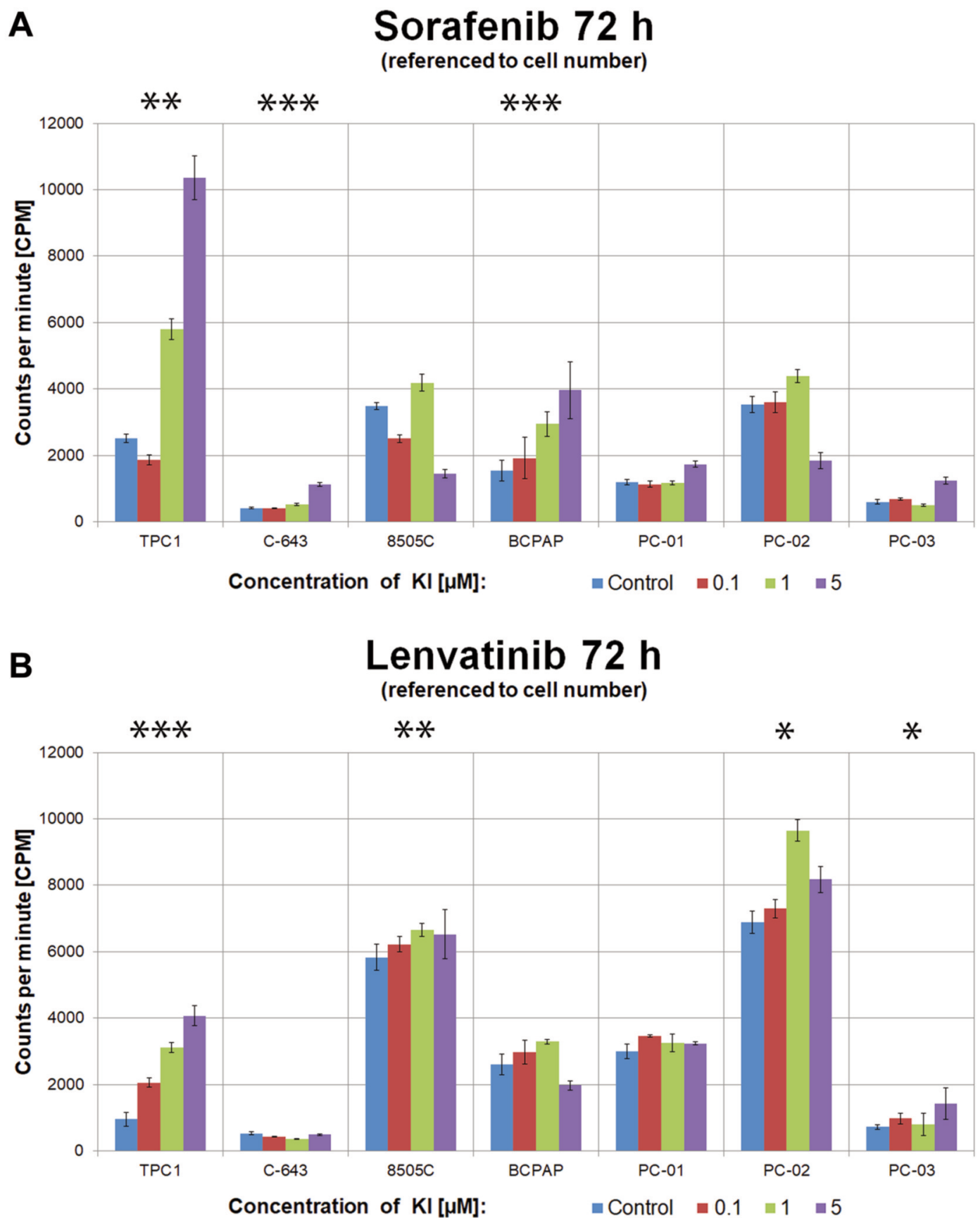

Figure 2. Continued

accumulation of purple-colored formazan, a product of the Nicotinamide adenine dinucleotide phosphate (NADPH)-dependent, succinate-dehydrogenase-catalyzed enzymatic transformation of the MTT reagent. The quantification of cytoviability was conducted through a spectro-photometrical absorptiometry at a wavelength of $570 \mathrm{~nm}$ in comparison to the reference wavelength of $630 \mathrm{~nm}$ in an "Emax precision microplate reader" Enzyme-Linked Immunosorbent Assay (ELISA)-apparatus (Molecular Devices, San
Jose, CA, USA), and the software "SoftMax Pro 6, version 6.4" was used to process the data.

In the meantime, the wells serving as negative controls in the later radioactivity uptake measurements were incubated with 240 $\mu \mathrm{M}$ of sodium perchlorate monohydrate (Irenat ${ }^{\circledR}$ ) for $30 \mathrm{~min}$, and exposed to an activity of $1 \mathrm{MBq}$ of technetium-99m for $1 \mathrm{~h}$. Excess solution was washed out with $0.9 \%$ sodium chloride and the adherent cell layers' dissolution was promoted by the application of 


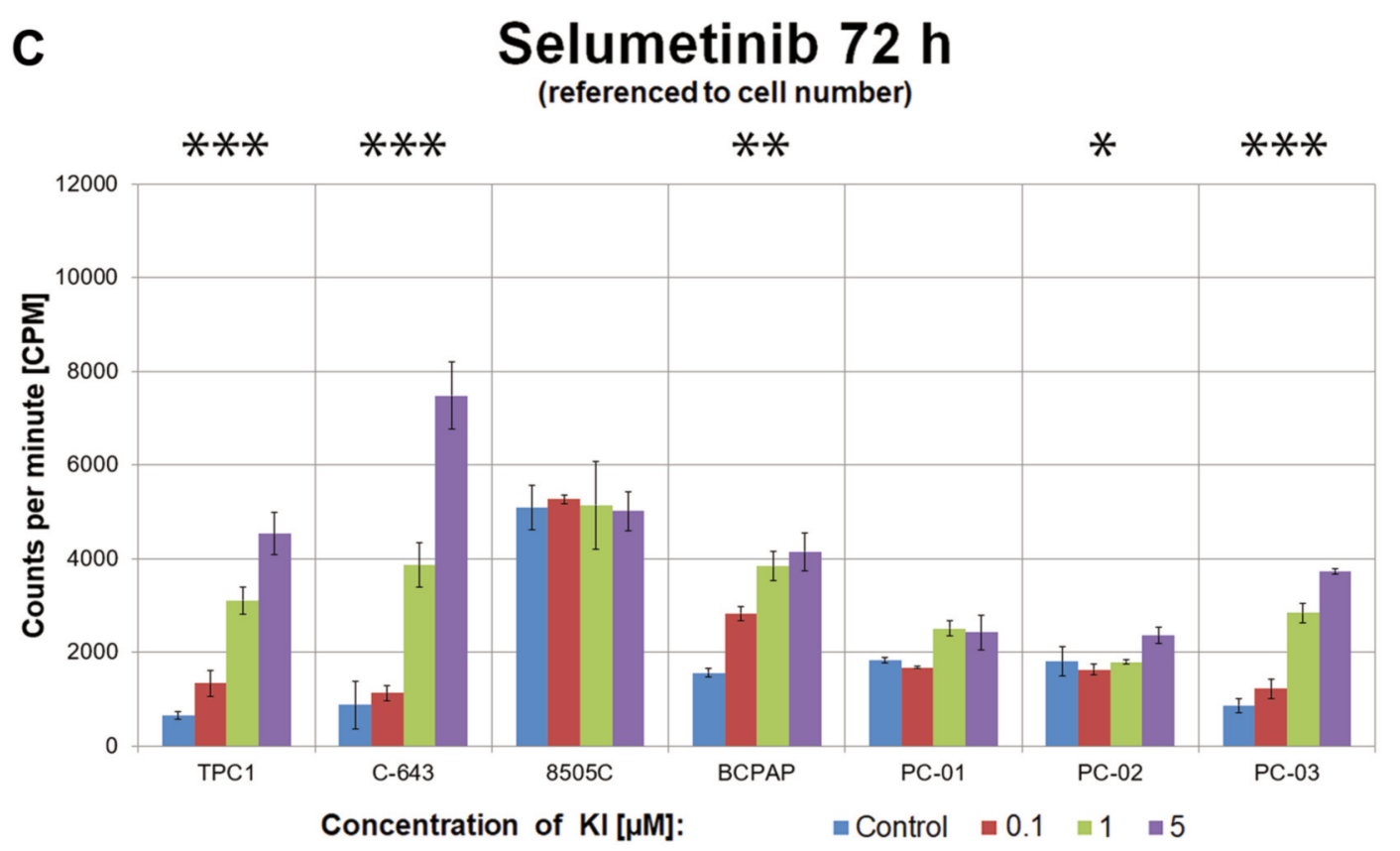

Figure 2. Comparison of the dose-dependent technetium-99m uptake values of all examined cell lines after treatment with sorafenib (2a), lenvatinib (2b) and selumetinib (2c) in the concentrations of $0.1 \mu \mathrm{M}, 1 \mu \mathrm{M}$ and $5 \mu \mathrm{M}$ for $72 \mathrm{~h}$, referenced to the cell count. The arithmetic means of the radioactivity uptake, measured in counts per minute, after $72 \mathrm{~h}$ of incubation with the respective KI of the labelled concentration and exposure to $1 \mathrm{MBq}$ of technetium-99m for 60 minutes compared to the untreated control is depicted in the form of colored bars for all examined cell cultures. All measurements are referenced to the cell count as assessed via MTT assay. The standard deviation values are marked as vertical line segments. No label: non-significant, ${ }^{*} p<0.05, * * p<0.01, * * * p<0.001$ according to Jonckheere trend test.

$1 \mathrm{ml} 1$-molar sodium hydroxide for $10 \mathrm{~min}$. The wells' contents were pipetted into separate glass tubes, which were put into the gamma counter for a one-min measurement protocol to quantify the absorbed radioactivity. We used technetium-99m as a surrogate for iodine-131 due to its lower radiation toxicity, better availability and sodium-iodide-symporter (NIS)-specificity.

For the cytoviability analysis, arithmetic means and standard deviations were calculated from the MTT assay results. The technetium-99m-uptake in the cells was assessed using the following method: By subtracting the blank value from the raw counts per minute (CPM) values, the confounding effect for the remaining radioactivity in the wells was reduced. The uptake value was referenced to the cell number by division of the results through the respective averaged MTT value to correct for the influence of differences in growth between the cell lines. From the processed data, calculation of arithmetic means and standard deviations was conducted again within every subtest series, and graphically displayed in the form of bar diagrams.

Statistical significance was evaluated through a one-sided Jonckheere trend test, a non-parametric operation that examines a multitude of random samples for a monotonous trend. In case of the cytoviability analyses we tested for a decreasing, in case of the radioactivity uptake for an increasing trend. The calculations for this study were performed using the software „R 3.4.1.“ and “Microsoft ${ }^{\circledR}$ Excel $^{\circledR}$ Home and Student 2007". All tables and figures were created in “Microsoft ${ }^{\circledR}$ Excel $^{\circledR}$ Home and Student 2007". Due to small sample sizes, $p$-values were calculated from a permutated instead of an asymptotical distribution. $p$-Values smaller than 0.05 , 0.01 and 0.001 were rated as significant $(*)$, highly significant $(* *)$ and extremely significant $(* * *)$, respectively. The calculations were performed using the software „R 3.4.1.“.

\section{Results}

The influence of the three KIs showed a huge variation among the different cell lines (Figure $2 \mathrm{a}, \mathrm{b}$ and c). These findings are underlined by the percentual calculations of the uptake variation as presented in Tables II and III. The application of sodium perchlorate monohydrate did not lead to a sufficient blockade of technetium-99m-uptake in our experiment and the values of measurements were nearly identical or partially even slightly higher than the unblocked results. The negative controls also showed almost the same increase in uptake with higher concentrations of the applied $\mathrm{KI}$ as the probes that were not treated with perchlorate solution. Hence, the negative controls were not included in the graphical presentation of the uptake.

The well differentiated PTC cell line TPC1, showed a significant uptake increase in all three drug treatment experiments. Treatment with sorafenib, lenvatinib and selumetinib resulted in maximum percentual technetium-99m 
Table II. Dose-dependent percentual increases of technetium-99m uptake from the reference cell lines after treatment with sorafenib, lenvatinib and selumetinib in the concentrations of $0.1 \mu \mathrm{M}, 1 \mu \mathrm{M}$ and $5 \mu M$ for $72 h$, referenced to the cell count. The table shows the kinase inhibitor (KI)-dependent percentual increases of the counts per min in comparison to the untreated control, referenced to the cell count as assessed via MTT assay, as a surrogate for the technetium-99m uptake in all four reference cell cultures. The baseline value of the control was set as the $100 \%$ marker.

Increase of technetium-99m uptake after KI treatment Reference cell lines

\begin{tabular}{lccc}
\hline Reference cell line TPC1 & & & \\
Concentration $[\mu \mathrm{M}]$ & Sorafenib & Lenvatinib & Selumetinib \\
0.1 & $-26 \%$ & $115 \%$ & $106 \%$ \\
1 & $131 \%$ & $226 \%$ & $378 \%$ \\
5 & $312 \%$ & $326 \%$ & $598 \%$ \\
Reference cell line C-643 & & & \\
Concentration $[\mu \mathrm{M}]$ & Sorafenib & Lenvatinib & Selumetinib \\
0.1 & $-3 \%$ & $-18 \%$ & $29 \%$ \\
1 & $25 \%$ & $-32 \%$ & $343 \%$ \\
5 & $167 \%$ & $-8 \%$ & $759 \%$ \\
Reference cell line 8505C & & & \\
Concentration $[\mu \mathrm{M}]$ & Sorafenib & Lenvatinib & Selumetinib \\
0.1 & $-28 \%$ & $7 \%$ & $4 \%$ \\
1 & $20 \%$ & $14 \%$ & $1 \%$ \\
5 & $-58 \%$ & $12 \%$ & $-1 \%$ \\
Reference cell line BCPAP & & & \\
Concentration $[\mu \mathrm{M}]$ & Sorafenib & Lenvatinib & Selumetinib \\
0.1 & $25 \%$ & $14 \%$ & $82 \%$ \\
1 & $91 \%$ & $26 \%$ & $147 \%$ \\
5 & $157 \%$ & $-24 \%$ & $166 \%$ \\
\hline
\end{tabular}

uptake values of $312 \%, 326 \%$ and $598 \%$, respectively, compared to the untreated control. A similarly positive result was observed in the BCPAP (PDTC) experiments using selumetinib and sorafenib. A concentration of $5 \mu \mathrm{M}$ led to statistically significant uptake increases of $166 \%$ and $157 \%$, respectively. High dosages of lenvatinib, however, led to a decrease of $24 \%$, following a slight increase in the low-dose tests. The uptake improvement in the experiments with the two established ATC cell lines were very variable. 8505C showed only a minimal effect for selumetinib and lenvatinib, even though the calculated $p$-value suggested statistical significance in the latter case. Sorafenib demonstrated a highly volatile uptake profile with a drop of $-58 \%$ beyond the control value under the highest concentration. C-643 led to a significant count gain of $167 \%$ with sorafenib, whereas lenvatinib hardly affected the cells at all and resulted in an uptake drop. The highest concentration of selumetinib produced a $759 \%$ rise in uptake, which was the clearest percentual boost of all test runs and was statistically significant.

Among the primary cell cultures, PC-01 did not show any increased uptake for sorafenib at low concentrations, whereas $5 \mu \mathrm{M}$ accounted for a $45 \%$ rise in uptake. In addition,
Table III. Dose-dependent percentual increase of technetium-99m uptake of the primary cell lines after treatment with sorafenib, lenvatinib and selumetinib in the concentrations of $0.1 \mu \mathrm{M}, 1 \mu \mathrm{M}$ and $5 \mu M$ for $72 h$, referenced to the cell count. The table shows the kinase inhibitor (KI)-dependent percentual increase in the counts per minute in comparison to the untreated control, referenced to the cell count as assessed via MTT assay, as a surrogate for the technetium-99m uptake in all three primary cell cultures. The baseline value of the control was set as the 100\% marker.

Increase of technetium-99m uptake after KI treatment Primary cell lines

\begin{tabular}{lccc}
\hline Primary culture PC-01 & & & \\
Concentration $[\mu \mathrm{M}]$ & Sorafenib & Lenvatinib & Selumetinib \\
0.1 & $-5 \%$ & $15 \%$ & $-8 \%$ \\
1 & $-2 \%$ & $8 \%$ & $37 \%$ \\
5 & $45 \%$ & $8 \%$ & $33 \%$ \\
Primary culture PC-02 & & & \\
Concentration $[\mu \mathrm{M}]$ & Sorafenib & Lenvatinib & Selumetinib \\
0.1 & $2 \%$ & $6 \%$ & $-10 \%$ \\
1 & $24 \%$ & $40 \%$ & $-1 \%$ \\
5 & $-48 \%$ & $19 \%$ & $30 \%$ \\
Primary culture PC-03 & & & \\
Concentration $[\mu \mathrm{M}]$ & Sorafenib & Lenvatinib & Selumetinib \\
0.1 & $14 \%$ & $36 \%$ & $42 \%$ \\
1 & $-18 \%$ & $10 \%$ & $230 \%$ \\
5 & $104 \%$ & $98 \%$ & $333 \%$ \\
\hline
\end{tabular}

lenvatinib, at the lowest concentration, reached a maximum increase of $15 \%$, and selumetinib at the concentrations of 1 $\mu \mathrm{M}$ and $5 \mathrm{mM}$ led to a gain of nearly a third of the baseline counts. There was no statistical significance in any of the constellations. In the experiments with the ATC PC-02, the highest doses of sorafenib and lenvatinib led to a drop in uptake after an initial increase in the lower concentrations. The lenvatinib experiments illustrated an overall significant upward trend. Only the highest concentration of selumetinib led to a significant increase of $30 \%$ in the uptake of technetium-99m compared to the control. The most striking dose-dependent uptake increase among the primary cultures was observed in the experiments with PC-03, also an ATC. Five $\mu \mathrm{M}$ of selumetinib, sorafenib and lenvatinib induced partially significant elevations in counts per min of $333 \%$, $104 \%$ and $98 \%$, respectively. However, $1 \mu \mathrm{M}$ of lenvatinib and sorafenib decreased uptake values. Conclusively, the most obvious percentual increases, found in the experiments using TPC1, C-643 and PC-03, were all allotted to the application of $5 \mu \mathrm{M}$ of selumetinib.

\section{Discussion}

Radioiodine-refractory thyroid carcinomas are mostly irresponsive to common treatment strategies and are associated with lower survival rates and worse prognoses. A 
possible therapeutic approach is the restitution of NISexpression and, subsequently, of radioiodine avidity, through KI therapy (12). Sorafenib, lenvatinib and selumetinib are three agents that have already been successfully used in the therapy of radioiodine-refractory thyroid cancer. Still, practical experience has shown variable efficacy and relevant toxicity for all three KIs (14-16), as well as the development of resistance against sorafenib in long-term applications (17).

To assess the effect of KIs on the cells' ability to accumulate technetium-99m, used as a surrogate for the expression of NIS, and therefore, evaluate their redifferentiation potential, the cells in our experiment were exposed to the radioactive tracer after KI pretreatment. The uptake was quantified and referenced to the number of vital cells.

After KI pretreatment, the radioactivity uptake of the cells was partially increased in our setting. Exposure to $5 \mu \mathrm{M}$ of sorafenib resulted in an increase in the uptake of technetium$99 \mathrm{~m}$ in multiple test series. However, cell lines reacted differently to increased dosages. The cultures $8505 \mathrm{C}$ and PC02 showed declines in uptake measurements even beyond control values after the elevation of the concentration from $1 \mu \mathrm{M}$ to $5 \mu \mathrm{M}$, whereas the cells C-643, PC-01 and PC-03 were not significantly affected by low-dose treatments and only showed higher counts per min at $5 \mu \mathrm{M}$. The observed effects in ATC were smaller than in PTC and PDTC. International publications also describe a poor effect of sorafenib on ATC in terms of response rates to oncological therapy $(18,19)$. Altogether, our results argue against a relevant redifferentiation effect of sorafenib, which is supported by a clinical phase-II study by Hoftijzer et al. investigating the uptake of radioiodine following a 26-week therapy cycle with $400 \mathrm{mg}$ sorafenib administered orally twice a day (20). Inhibition of tumor growth, progression and angiogenesis, appear to play a more important role in the drug's potency (17).

We also observed varying results using lenvatinib. Five $\mu \mathrm{M}$ led to an increased radioactivity uptake in most experiments. However, the cell lines C-643 and PC-01 were nearly refractory to all three concentrations, with only minor fluctuations in measurements. Among the reference cell lines, we observed a better response with higher differentiation, but the results in the primary cultures contradicted this hypothesis. A Japanese phase-II trial also found weaker, but still positive responses in ATC (21). The less affected cell lines 8505C, C-643, BCPAP and PC-01 all share a TP53 mutation that is a common feature in poorly differentiated or anaplastic tumors (8). TPC1, the cell line with the best response, harbors an H-Ras mutation and a driver mutation, which is a RET/PTC-rearrangement. Sherman et al. proved a significantly better progression-free survival rate of $80 \%$ in $\mathrm{N}$ - and $\mathrm{K}$-Ras-mutants compared to $20 \%$ in wild type gene carriers in their phase-II trial from 2011 (22). Yet, the later "SELECT" study could not demonstrate an influence of Ras mutations on the efficacy of lenvatinib (15). Conclusively, the final proof for a redifferentiating potential of lenvatinib is incomplete. The leading mechanism in lenvatinib's impact on thyroid carcinomas is assumed to be angiogenesis inhibition (23).

The only drug with a potential redifferentiation effect to date is the MEK inhibitor selumetinib, as shown in a small pilot study (10). It also showed the highest increase in technetium$99 \mathrm{~m}$ uptake in our experiments. A correlation to the tumor type could not be detected as both - the best and the worst response to selumetinib - could be allotted to an ATC cell line. We found a significantly better response in C-643 and PC-03, both ATC, than in more differentiated cell lines. This exceeded our expectations, since ATC have a lower iodine metabolizing function per se. A plausible explanation for these outcomes could not be derived from our set-up. Similar observations were made regarding the mutational status. A Ras mutation was found in the well responding cell cultures C-643 and TPC1, but also in the immune cell line $8505 \mathrm{C}$. Nevertheless, publicized trials indicate a greater sensitivity to selumetinib in Ras mutated cells compared to wild type ones $(10,16)$. In our setting, a selumetinib-dependent redifferentiation could neither be definitely proven nor denied. A recent in vitro study at our institution examined the effects of selumetinib on the same four reference cell lines that were used in our experiments and found a significant up-regulation of both - NIS protein level and radioiodine uptake - in TPC1 cells and higher NIS expression in BCPAP cells, indicating a redifferentiation potential, while $8505 \mathrm{C}$ and C643 showed decreased NIS levels and also, a lower uptake in the latter case (24).

Conclusively, our results imply a positive influence of all three investigated drugs on the uptake of technetium- $99 \mathrm{~m}$ into the carcinoma cells, especially in the case of selumetinib. Correlations between KI sensitivity and carcinoma type or mutational status remained uncertain, showing the requirement for further studies. The interpretation of the data was complicated by the small number of available primary cell cultures and an over-representation of ATC in comparison to DTC, even though we tried to match the cell selection with established cell lines in a corresponding ratio. Furthermore, the primary cell cultures presented a more reluctant and unstable growth pattern compared to the established reference cultures, and a higher natural cell death rate before the KI or the technetium-99m were administered. Thus, a confounding effect cannot be ruled out, despite the fact that the uptake values were referenced to the cell count. Furthermore, the decision to evaluate trends within the tested cell lines might have led to an overestimated statistical significance in a subset of test runs with weak absolute response rates, such as the experiment with lenvatinib in $8505 \mathrm{C}$. The insufficiency of the blockage with sodium perchlorate monohydrate remained unclear, but accounted for a less reliable negative control in our study. In most test series, the measurements 
with and without the blocking solution hardly differed or turned out to be higher after perchlorate application. Inclusion of the negative control values into the statistical calculations led to distortion of the uptake profiles. Nevertheless, the rise in count rates in both, the blocked and non-blocked test series, suggests that the uptake increase does not originate solely from the redifferentiation of the carcinoma cells, but also from unspecific side effects. It can be assumed that the dose-dependent cytotoxicity of the KI led to a progressive destruction of the cell membrane integrity and subsequently provoked a technetium-99m influx into the cells that was independent of symporter mechanisms. This theory is supported by a study that reported an increasing release of lactate dehydrogenase (LDH), a higher activity of caspases 3 and 7, and an increase in the SubG1 cell cycle fraction, which correlates with the induction of apoptosis, augmentation of deoxyribonucleic acid (DNA) fragmentation and cell cycle arrest after treatment with sorafenib as compared to controls (25).

\section{Conclusion}

In this study, based on in vitro experiments on four reference and three primary cell cultures, the latter retrieved from tumor tissues from patients at our institution, we examined the effect of sorafenib, lenvatinib and selumetinib in the concentrations of $0.1,1$ and $5 \mu \mathrm{M}$ on the uptake of technetium-99m into thyroid carcinoma cells in reference to the cell number. All three tested KIs positively influenced the technetium-99m uptake when applied in the concentration of $5 \mu \mathrm{M}$ and led to a cell count reduction in the majority of the experiments, especially when selumetinib was used. Nevertheless, we detected major differences in the extent of the reaction to the KIs between the various cell lines, and certain drawbacks in our experimental setting complicated the final interpretation of the results. All of these aspects underline the importance of and the recommendation to develop a standard operating procedure for patient preselection preceding a KI-based pharmacotherapy. However, KIs remain a viable and promising option in cases of progressive and dedifferentiated thyroid cancer refractory to conventional therapy.

\section{Conflicts of Interest}

The Authors declare that they have no conflicts of interest in regards to this study.

\section{Authors' Contributions}

All Authors contributed to the study conception and design. Material preparation, data collection and the analysis were performed by Anna Anschlag, Annette Wunderlich and Brandon Greene. The first draft of the manuscript was written by Anna Anschlag and corrected by Lorianna Könneker, Markus Luster, James Nagarajah, Andreas Pfestroff, Sabine Wächter and Annette Wunderlich. All Authors commented on previous versions of the manuscript and read and approved the final manuscript.

\section{References}

1 German Cancer Register Data 2016: Thyroid Carcinoma by Sex, 1999-2016. Berlin, Robert Koch Institut, Center for Cancer Register Data, 2016. Available at: https://www.krebsdaten.de/ Krebs/DE/Content/Krebsarten/Schilddruesenkrebs/schilddruesen krebs_node.html [Last accessed on November 24, 2020]

2 Global Health Data Exchange 2019: Global Thyroid Carcinoma Incidence by Sex, 2019. Seattle, Institute for Health Metrics and Evaluation, 2020. Available at: http://ghdx.healthdata.org/gbdresults-tool [Last accessed on November 24, 2020]

3 Fugazzola L, Elisei R, Fuhrer D, Jarzab B, Leboulleux S, Newbold K and Smit J: 2019 European Thyroid Association guidelines for the treatment and follow-up of advanced radioiodine-refractory thyroid cancer. Eur Thyroid J 8: 227-245, 2019. PMID: 31768334. DOI: $10.1159 / 000502229$

4 De la Fouchardière C, Decaussin-Petrucci M, Berthiller J, Descotes F, Lopez J, Lifante JC, Peix JL, Giraudet AL, Delahaye A, Masson S, Bournaud-Salinas C and Borson Chazot F: Predictive factors of outcome in poorly differentiated thyroid carcinomas. Eur J Cancer 92: 40-47, 2018. PMID: 29413688. DOI: 10.1016/j.ejca.2017.12.027

5 Klein Hesselink EN, Steenvoorden D, Kapiteijn E, Corssmit EP, van der Horst-Schrivers AN, Lefrandt JD, Links TP and Dekkers OM: Therapy of endocrine disease: response and toxicity of small-molecule tyrosine kinase inhibitors in patients with thyroid carcinoma: a systematic review and meta-analysis. Eur J Endocrinol 172(5): R215-R225, 2015. PMID: 25572389. DOI: 10.1530/EJE-14-0788

6 Wells SA Jr, Robinson BG, Gagel RF, Dralle H, Fagin JA, Santoro M, Baudin E, Elisei R, Jarzab B, Vasselli JR, Read J, Langmuir P, Ryan AJ and Schlumberger MJ: Vandetanib in patients with locally advanced or metastatic medullary thyroid cancer: a randomized, double-blind phase III trial. J Clin Oncol 30: 134-141, 2011. PMID: 22025146. DOI: $10.1200 / \mathrm{JCO}$. 2011.35.5040

7 Dietlein $M$, Luster $M$ and Reiners C: Differenziertes Schilddrüsenkarzinom: Behandlungskorridore und interdisziplinäre Konzepte. In: Thieme-Refresher Onkologie, Update 2013/2014. Stuttgart, Thieme, pp. R21-R23, 2013.

8 Rashid M, Agarwal A, Pradhan R, George N, Kumari N, Sabaretnam M, Chand G, Mishra A, Agarwal G and Mishra SK: Genetic alterations in anaplastic thyroid carcinoma. Indian $\mathrm{J}$ Endocrinol Metab 23(4): 480-485, 2019. PMID: 31741910. DOI: 10.4103/ijem.IJEM_321_19

9 Kreissl MC, Janssen MJR and Nagarajah J: Current treatment strategies in metastasized differentiated thyroid cancer. J Nucl Med 60(1): 9-15, 2019. PMID: 30190306. DOI: 10.2967/ jnumed.117.190819

10 Ho A, Grewal RK, Leboeuf R, Sherman EJ, Pfister DG, Deandreis D, Pentlow KS, Zanzonico PB, Haque S, Gavane S, Ghossein RA, Ricarte-Filho JC, Domínguez JM, Shen R, Tuttle RM, Larson SM and Fagin JA: Selumetinib-enhanced radioiodine uptake in advanced thyroid cancer. N Engl J Med 368: 623-632, 2013. PMID: 23406027. DOI: 10.1056/NEJMoa1209288 
11 Lorusso L, Pieruzzi L, Biagini A, Sabini E, Valerio L, Giani C, Passannanti P, Pontillo-Contillo B, Battaglia V, Mazzeo S, Molinaro E and Elisei R: Lenvatinib and other tyrosine kinase inhibitors for the treatment of radioiodine refractory, advanced, and progressive thyroid cancer. Onco Targets Ther 9: 6467-6477, 2016. PMID: 27799794. DOI: 10.2147/OTT.S84625

12 Buffet C, Wassermann J, Hecht F, Leenhardt L, Dupuy C, Groussin L and Lussey-Lepoutre C: Redifferentiation of thyroid cancers. Endocr Relat Cancer 27: R113-R132, 2020. PMID: 32191916. DOI: 10.1530/ERC-19-0491

13 Eckhardt S, Hoffmann S, Damanakis AI, Di Fazio P, Pfestroff A, Luster M, Wunderlich A and Bartsch DK: Individualized multimodal treatment strategy for anaplastic thyroid carcinoma - case report of long-term remission and review of literature. Int J Surg Case Rep 25(2016): 174-178, 2016. PMID: 27379749. DOI: $10.1016 /$ j.ijscr.2016.06.013

14 Brose M, Nutting CM, Jarzab B, Elisei R, Siena S, Bastholt L, de la Fouchardiere C, Pacini F, Paschke R, Shong YK, Sherman SI, Smit JW, Chung J, Kappeler C, Peña C, Molnár I and Schlumberger MJ: Sorafenib in locally advanced or metastatic, radioactive iodinerefractory, differentiated thyroid cancer: a randomized, double-blind, phase 3 trial. Lancet 384(9940): 319-328, 2014. PMID: 24768112. DOI: 10.1016/S0140-6736(14)60421-9

15 Schlumberger M, Tahara M, Wirth LJ, Robinson B, Brose MS, Elisei R, Habra MA, Newbold K, Shah MH, Hoff AO, Gianoukakis AG, Kiyota N, Taylor MH, Kim SB, Krzyzanowska MK, Dutcus CE, de las Heras B, Zhu J and Sherman SI: Lenvatinib versus placebo in radioiodine-refractory thyroid cancer. N Engl J Med 372(7): 621-630, 2015. PMID: 25671254. DOI: $10.1056 /$ NEJMoa1406470

16 Hayes DN, Lucas AS, Tanvetyanon T, Krzyzanowska MK, Chung CH, Murphy BA, Gilbert J, Mehra R, Moore DT, Sheikh A, Hoskins J, Hayward MC, Zhao N, O'Connor W, Weck KE, Cohen RB and Cohen EE: Phase II efficacy and pharmacogenomic study of selumetinib (AZD6244; ARRY142886) in iodine-131 refractory papillary thyroid carcinoma with or without follicular elements. Clin Cancer Res 18(7): 2056-2065, 2012. PMID: 22241789. DOI: 10.1158/10780432.CCR-11-0563

17 Pitoia F and Jerkovich F: Selective use of sorafenib in the treatment of thyroid cancer. Drug Des Devel Ther 10: 11191131, 2016. PMID: 27042004. DOI: 10.2147/DDDT.S82972

18 Ferrari SM, Elia G, Ragusa F, Ruffilli I, La Motta C, Paparo SR, Patrizio A, Vita R, Benvenga S, Materazzi G, Fallahi P and Antonelli A: Novel treatments for anaplastic thyroid carcinoma. Gland Surg 9(Suppl 1): S28-S42, 2020. PMID: 32055496. DOI: $10.21037 / \mathrm{gs} .2019 .10 .18$
19 Savvides P, Nagaiah G, Lavertu P, Fu P, Wright JJ, Chapman R, Wasman J, Dowlati A and Remick SC: Phase II trial of sorafenib in patients with advanced anaplastic carcinoma of the thyroid. Thyroid 23(5): 600-604, 2013. PMID: 23113752. DOI: 10.1089/thy.2012.0103

20 Hoftijzer H, Heemstra KA, Morreau H, Stokkel MP, Corssmit EP, Gelderblom H, Weijers K, Pereira AM, Huijberts M, Kapiteijn E, Romijn JA and Smit JW: Beneficial effects of sorafenib on tumor progression, but not on radioiodine uptake, in patients with differentiated thyroid carcinoma. Eur J Endocrinol 161: 923-931, 2009. PMID: 19773371. DOI: 10.1530/EJE-09-0702

21 Takahashi S, Kiyota N, Yamazaki T, Chayahara N, Nakano K, Inagaki L, Toda K, Enokida T, Minami H, Imamura Y, Fukuda N, Sasaki T, Suzuki T, Ikezawa H, Dutcus CE and Tahara M: A Phase II study of the safety and efficacy of lenvatinib in patients with advanced thyroid cancer. Future Oncol 15(7): 717-726, 2019. PMID: 30638399. DOI: 10.2217/fon-2018-0557

22 Sherman SI: Targeted therapies for thyroid tumors. Mod Pathol 24: S44-S52, 2011. PMID: 21455200. DOI: 10.1038/modpathol. 2010.165

23 Cabanillas ME, Ryder M and Jimenez C: Targeted therapy for advanced thyroid cancer: kinase inhibitors and beyond. Endocr Rev 40(6): 1573-1604, 2019. PMID: 31322645. DOI: 10.1210/ er.2019-00007

24 Wächter S, Wunderlich A, Greene BH, Roth S, Elxnat M, Fellinger SA, Verburg FA, Luster M, Bartsch DK and Di Fazio P: Selumetinib activity in thyroid cancer cells: modulation of sodium iodide symporter and associated miRNAs. Int J Mol Sci 19(7): 2077, 2018. PMID: 30018229. DOI: 10.3390/ ijms 19072077

25 Broecker-Preuss M, Müller S, Britten M, Worm K, Schmid KW, Mann K and Fuhrer D: Sorafenib inhibits intracellular signaling pathways and induces cell cycle arrest and cell death in thyroid carcinoma cells irrespective of histological origin or BRAF mutational status. BMC Cancer 15: 184, 2015. PMID: 25879531. DOI: $10.1186 / \mathrm{s} 12885-015-1186-0$
Received November 25, 2020

Revised December 8, 2020

Accepted December 9, 2020 